\title{
Cav3.2 calcium channel interactions with the epithelial sodium channel ENaC
}

\author{
Agustin Garcia-Caballero', Maria A. Gandini', Shuo Huang ${ }^{1}$, Lina Chen'1, Ivana A. Souza', Yan L. Dang², \\ M. Jackson Stutts ${ }^{2}$ and Gerald W. Zamponi ${ }^{1^{*}}$ (D)
}

\begin{abstract}
This study describes the functional interaction between Cav3.2 calcium channels and the Epithelial Sodium Channel (ENaC). $\beta$-ENaC subunits showed overlapping expression with endogenous Cav3.2 calcium channels in the thalamus and hypothalamus as detected by immunostaining. Moreover, $\beta$ - and $\gamma-\mathrm{ENaC}$ subunits could be co-immunoprecipitated with Cav3.2 calcium channels from brain lysates, dorsal horn and lumbar dorsal root ganglia. Mutation of a cluster of lysines present in the intracellular N-terminus region of $\beta$-ENaC (K4R/ K5R/ K9R/ K16R/ K23R) reduced interactions with Cav3.2 calcium channels. A $\beta Y$-ENaC channels enhanced Cav3.2 calcium channel trafficking to the plasma membrane in tsA-201 cells. This effect was reciprocal such that Cav3.2 channel expression also enhanced $\beta$-ENaC trafficking to the cell surface. T-type current density was increased when fully assembled a $\beta \gamma$-ENaC channels were transiently expressed in CAD cells, a neuronal derived cell line. Altogether, these findings reveal ENaC as an interactor and potential regulator of Cav3.2 calcium channels expressed in neuronal tissues.
\end{abstract}

Keywords: Cav3.2 calcium channels, Epithelial Sodium Channel (ENaC), Dorsal root ganglia (DRG), Dorsal horn

\section{Introduction}

The Epithelial Sodium Channel $(\mathrm{ENaC})$ is a key regulator of sodium absorption in a variety of tissues. It fine tunes sodium in the nephron and the colonic epithelia [1] where it helps to maintain total body salt and volume homeostasis. In the pulmonary airway epithelia $\mathrm{ENaC}$ regulates the composition and depth of the airway surface liquid to maintain mucociliary clearance $[2,3]$. Malfunction of $\mathrm{ENaC}$ in these tissues results in various cardiovascular [4] and lung diseases, such as cystic fibrosis [5]. ENaC typically consists of three subunits $(\alpha, \beta$, and $\gamma$ ) which when co-assembled form a sodium selective pore [6]. Each subunit is composed of two transmembrane domains with an amino-terminal (N-terminal) cytosolic domain, a large extracellular loop and a cytosolic carboxyl-terminus (C-terminus) [3]. Gain or loss of function mutations in all $\mathrm{ENaC}$ subunits result in disorders such as hypertension or Liddle's Syndrome and pseudohypoaldosteronism [4, 7].

\footnotetext{
* Correspondence: zamponi@ucalgary.ca

${ }^{1}$ Molecular Neuroscience, Department of Physiology and Pharmacology, Hotchkiss Brain Institute and Alberta Children's Hospital Research Institute, Cumming School of Medicine, University of Calgary, 3330 Hospital Dr. NW, Calgary T2N 4N1, Canada

Full list of author information is available at the end of the article
}

Importantly, ENaC is inhibited by the Cystic Fibrosis transmembrane conductance regulator (CFTR) via channel / channel interactions [8]. $\mathrm{ENaC}$ can also interact with the thiazide-sensitive sodium chloride cotransporter (NCC) in the kidney [9], suggesting that these channels can readily interact with other membrane proteins. $\mathrm{ENaC}$ expression is not limited to non-neuronal tissues as evident from reported expression in mechanosensory neurons [10], dorsal root ganglia (DRG) [11] and brain. However, the function of $\mathrm{ENaC}$ channels in neurons has not been well described.

Certain types of sensory neurons express Cav3.2 calcium channels $[12,13]$ These channels belong to the family of low-voltage gated T-type calcium channels [14]. Their biophysical properties, such as low voltage thresholds for activation and inactivation, fast inactivation and rebound bursting, are important for neuronal excitability in both the central and peripheral nervous systems [14, 15]. Cav3.2 calcium channels are also expressed in the thalamus [15] where they play an important role in epilepsy [16-18]. Importantly, Cav3.2 calcium channels can form channel complexes with members of the potassium channel family such as $\mathrm{Kv} 4, \mathrm{KCa} 1.1$, and $\mathrm{KCa} 3.1$ to regulate neuronal activity [19-21]. 
Because of the overlap in $\mathrm{ENaC}$ and Cav3.2 channel expression in sensory neurons, and the reported inhibitory effect of intracellular calcium on the open probability of $\mathrm{ENaC}$ and on $\mathrm{ENaC}$ expression [22-24], we tested whether Cav3.2 channels may form a protein complex with $\mathrm{ENaC}$. We find that specific $\mathrm{ENaC}$ channel subunits interact with Cav3.2 channels and reciprocally regulate each other's membrane expression.

\section{Methods}

\section{Cell culture and transfection}

Human embryonic kidney tsA-201 cells were cultured as described previously [25]. Cells were transfected with calcium phosphate and used for biochemical and electrophysiological analysis $48-72 \mathrm{~h}$ post-transfection. Mouse CAD cells were cultured as described previously [13]. Cells were transfected with lipofectamine 2000 and used for biochemical assays $48-72 \mathrm{~h}$ post-transfection.

\section{Plasmids}

cDNAs encoding rat $\alpha-, \beta-$, and $\gamma$-ENaC with HA$\mathrm{N}$-terminal (HA-NT) epitope tags were used. WT and mutant constructs ( $\beta$-ENaC: K4R/ K5R/ K9R/ K16R/ $\mathrm{K} 23 \mathrm{R})$ were generated by PCR. Mutations were performed with the Quik change mutagenesis kit (Stratagene). The WT ENaC plasmids were provided by $\mathrm{B}$. Rossier (Université de Lausanne, Lausanne, Switzerland). The sequence of all plasmids was verified at the University of North Carolina sequencing facility.

\section{Biochemistry}

Co-immunoprecipitation (co-IP) experiments were followed by western blots. All tissue was derived from wildtype C57BL/6 mice. All procedures for tissue isolation were approved by the Animal Care Committee of the University of Calgary. Both lumbar DRG and dorsal horn tissue were lysed in modified RIPA buffer (in mM; 50 Tris, $100 \mathrm{NaCl}, 0.2 \%(v / \mathrm{v})$ Triton X-100, 0.2\% (v/v) NP-40, 10 EDTA + protease inhibitor cocktail, pH 7.5). Tissue lysates were used to immunoprecipitate Cav3.2 channels with a specific Cav3.2 polyclonal antibody (Sigma). Lysates were prepared by sonicating samples at $60 \%$ pulse for $10 \mathrm{~s}$ and by centrifugation at $13,000 \mathrm{rpm}$ for $15 \mathrm{~min}$ at $4{ }^{\circ} \mathrm{C}$. Supernatants were transferred to new tubes and solubilized proteins were incubated with 50 $\mathrm{ml}$ of Protein G/A beads (Piercenet) and $2 \mu \mathrm{g}$ of anti-Cav3.2 antibody overnight while tumbling at $4{ }^{\circ} \mathrm{C}$. Cav3.2 immunoprecipitates were washed twice with modified RIPA buffer and beads were aspirated to dryness. Laemmli buffer was added and samples were incubated at $96^{\circ} \mathrm{C}$ for $10 \mathrm{~min}$. Eluted samples were loaded on a $7.5 \%$ Tris-glycine gel or $10 \%$ Tris-glycine gel for inputs and resolved using SDS-PAGE. Samples were transferred to $0.45 \mathrm{~mm}$ polyvinylidenedifluoride (PDVF) membranes (Millipore) by dry-transfer with i-blot (Invitrogen). Membranes were probed for $\alpha$-ENaC (UNC1 19.2.1, 11,000), $\beta$-ENaC (Alomone, 1:500) or $\gamma$-ENaC subunits (StressMarq Biosciences, 1:500) with specific antibodies. Inputs, representing $4 \%$ of total lysate, were probed for alpha-tubulin (Abcam, 1:2000), as loading controls. Densitometry analysis was performed using the ImageJ program. Student T test, $p<0.05$ was considered significant $\left(" p<0.05,{ }^{* * *} p<0.01\right.$ and $\left.{ }^{* * * *} p<0.001\right)$.

\section{Surface labelling}

tsA-201 cells were transfected with either Cav3.2 cDNA alone or in combination with $\alpha-, \beta-$, and $\gamma-\mathrm{ENaC}$ subunits cDNA separately, or with all three ENaC subunits together $(10 \mu \mathrm{g}$ per $10-\mathrm{cm}$ dish). Cells grown in poly-lysine plates were washed twice with PBS buffer. Cells were pre-chilled on ice for $20 \mathrm{~min}$ and labeled with 0.75 $\mathrm{mg} \mathrm{ml}^{-1}$ sulfo-NHS-biotin in PBS-Ca-Mg (mM), 1 $\mathrm{MgCl} 2,0.1 \mathrm{CaCl} 2$, titrated to $\mathrm{pH} 8.3$ with $\mathrm{NaOH}$, while tumbling gently for $40 \mathrm{~min}$ at $4{ }^{\circ} \mathrm{C}$. Cells were washed twice with chilled PBS-Ca-Mg buffer and incubated in PBS-Ca-Mg buffer with $100 \mathrm{mM}$ glycine for $15 \mathrm{~min}$ at $4{ }^{\circ} \mathrm{C}$ to quench free biotin. Cells were washed again three times with chilled PBS-Ca-Mg buffer, then lysed with lysis buffer (in mM; 50 Tris, $100 \mathrm{NaCl}, 1 \%$ triton $\mathrm{X}-100$ (vol/vol), 1\% NP-40 (vol/vol), 0.2\% SDS (wt/ vol), $0.1 \%$ NaDeoxycholate (wt/vol), $20 \mathrm{NaF}, 10$ $\mathrm{Na}_{4} \mathrm{P}_{2} \mathrm{O}_{7}$ pyrophosphate, 10 EDTA + protease inhibitor cocktail (complete, Roche), pH 7.5). Cell lysates were prepared by sonicating samples at $60 \%$ pulse intensity for $10 \mathrm{~s}$ and by centrifugation at $14,000 \mathrm{rpm}$ for $15 \mathrm{~min}$ at $4{ }^{\circ} \mathrm{C}$. Supernatants were transferred to new tubes and solubilized proteins were incubated with $30 \mu \mathrm{l}$ of neutravidin beads (Pierce) overnight while tumbling at $4{ }^{\circ} \mathrm{C}$. Total inputs were taken from whole cell samples representing $4 \%$ of total protein. Samples were washed twice with $(\mathrm{mM}) 500 \mathrm{NaCl}, 50$ Tris $\mathrm{pH} 7.5$ buffer and once with $150 \mathrm{NaCl}, 50$ Tris pH 7.5 buffer. Laemmli buffer was added and samples were loaded on a $10 \%$ Tris-glycine gel after incubation for $10 \mathrm{~min}$ at $96^{\circ} \mathrm{C}$. Samples were transferred to $0.45 \mu \mathrm{m}$ polyvinylidene difluoride (PDVF) membranes by dry transfer using an I-blot machine (Invitrogen) and western blot analysis was performed using an anti-Cav3.2 antibody (Sigma) or an anti- $\beta$-ENaC antibody (Alomone).

\section{Immunostaining}

Sections were washed in 1X PBS 3 times before blocked for $1.5 \mathrm{~h}$ with vehicle $(0.5 \% \mathrm{BSA}+10 \% \mathrm{NGS}+0.3 \%$ Triton $\mathrm{X}-100$ in $1 \mathrm{X}$ PBS). Sections were then incubated with primary antibody (Rabbit anti $\beta$-ENaC, 1:200, Alomone labs, ASC-019; Mouse anti Cav3.2, 1:200, Novus, NBP1-22444) overnight at $4{ }^{\circ} \mathrm{C}$. Sections were washed 3 times in vehicle 
before incubation with secondary antibody (Goat anti rabbit, Alexa Fluor 488, 1:800, Invitrogen A11029; Goat anti mouse, Alexa Fluor 633, 1:800, Invitrogen A21070) for $1.5 \mathrm{~h}$ at room temperature. Sections were washed 3 times in vehicle, $1 \mathrm{X}$ PBS, and $0.5 \mathrm{X}$ PBS, respectively before being air dried and mounted on coverslips. Sections were scanned with either a Zeiss LSM 510 or a Leica TCS SP8 X confocal microscope.

\section{Electrophysiology}

Electrophysiological recordings were performed using the whole cell configuration of the patch-clamp technique at room temperature using an Axopatch $200 \mathrm{~B}$ amplifier (Axon Instruments, Union City, CA). Acquisition was performed using pClamp9 (Axon Instruments) and analysis was performed with Clampfit 9 (Axon Instruments) and GraphPad Prism. For CAD cells the internal recording solution contained (in $\mathrm{mM}$ ): $110 \mathrm{CsCl}, 3 \mathrm{MgATP}, 0.5$ Na-GTP, $2.5 \mathrm{MgCl}_{2}$, 5 D-glucose, 10 EGTA, 10 HEPES (pH 7.3 with $\mathrm{CsOH}$ ). The external solution contained (in $\mathrm{mM}): 10 \mathrm{BaCl}_{2}, 1 \mathrm{MgCl}_{2}, 140 \mathrm{TEACl}, 10 \mathrm{D}$-glucose, 10 HEPES (pH 7.2 with TEAOH). Cell with more than 100 pA current leak were not considered. Currents from tsA-201 cells were recorded using an external solution contained (in mM): $5 \mathrm{BaCl}_{2}, 1 \mathrm{MgCl}_{2}, 150 \mathrm{TEACl}, 10$ D-glucose, 10 HEPES (pH 7.2 with TEAOH).

The $I-V$ relationships were fitted with a Boltzmann equation of the form: $I=\operatorname{Gmax} *(V m-V r) /(1+$ $\left.\exp \left(-\left(V m-V_{1 / 2, a c t}\right) / k\right)\right)$, where $I$ is the peak current density, $V m$ is the membrane voltage, $\mathrm{V}_{1 / 2 \text {,act }}$ is the voltage for half activation, $V r$ is the reversal potential, and $k$ is the slope factor. Steady-state inactivation curves were fitted with the equation: I/Imax $=1 /\left(1+\exp \left(-\left(V-V_{1 /}\right.\right.\right.$ 2,inac $/ k)$ ), where $I / \operatorname{Imax}$ is the normalized current, $V$ is the conditioning voltage, $V_{1 / 2 \text {,inac }}$ is the voltage for half-inactivation and $k$ is the slope factor.

\section{Statistical analysis}

The significance of observed differences was evaluated by Student's $t$ tests and One Way Analysis of Variance as appropriate. A probability less than $5 \%$ was considered to be significant.

\section{Results}

\section{Cav3.2 channels and ENaC subunits interact}

Because there are several reports in the literature regarding the overlapping expression of both $\mathrm{ENaC}$ and Cav3.2 calcium channels in the brain, we first probed Cav3.2 immunoprecipitates from whole brain lysates with either $\alpha-, \beta-$, or $\gamma-\mathrm{ENaC}$ antibodies. $\beta$ - and $\gamma-\mathrm{ENaC}$ subunits bound to Cav3.2 channels were consistently detected (Fig. 1a-d). In contrast, the $\alpha-\mathrm{ENaC}$ antibody did not detect full-length or cleaved $\alpha$-ENaC subunits (Fig. 1a). If $\mathrm{ENaC}$ sodium channels interact with Cav3.2 calcium channels in the nervous system, then we might be able to detect channel complexes in peripheral neuronal tissues, where Cav3.2 calcium channels are expressed abundantly and play a role in peripheral pain transmission. Furthermore, $\beta$ - and $\gamma$-ENaC subunits, but not $\alpha-\mathrm{ENaC}$, have been shown to be expressed in dorsal root ganglia (DRG) at both protein and messenger levels [11]. Accordingly, we detected $\beta$-ENaC and $\gamma$ - ENaC subunits bound to Cav3.2 immunoprecipitates from mouse lumbar DRGs (L4-L6) and dorsal horns (Fig. 1e-h).

Next, we evaluated if Cav3.2 calcium channels expressed in certain regions of the brain may show overlapping expression with $\mathrm{ENaC}$. We stained mouse brain slices with Cav3.2 and $\beta$-ENaC antibodies and assessed the overlap in expression of the two proteins (Fig. 2a-d). For example, in the thalamus overlapping expression could be observed in 261 out of 276 cells examined whereas control slices did not yield a fluorescence signal (Fig. 2b, c, d). Similarly, we detected a strong co-localization in the hypothalamus where 591out of 618 cells co-stained for both Cav3.2 calcium channels and $\beta$-ENaC subunits (data not shown). Overlapping expression was also detected in the hippocampus (Fig. 2a).

These findings altogether suggest that Cav3.2 and $\mathrm{ENaC}$ show overlapping expression in the thalamic region, and that there are protein complexes between Cav3.2 calcium channels and $\beta$-ENaC subunits.

\section{The $\mathrm{N}$-terminus region of $\beta$ - $\mathrm{ENaC}$ contributes to Cav3.2 interactions}

Next, we asked if the N-Terminus tail of $\beta-\mathrm{ENaC}$ is responsible for the channel complex formation, more specifically if the lysines present in this intracellular region of $\beta$-ENaC are involved. We expressed WT or mutant $\beta$-ENaC subunits (K4R, K5R, K9R, K16R, K23R) in CAD cells and performed co-immunoprecipitations with this neuronal derived cell line. Binding of the mutant $\beta$-ENaC subunit to endogenous Cav3.2 channels was reduced by $50 \%$ compared to WT $\beta$-ENaC (Fig. 3a, b). This result strongly suggests that the cluster of lysines present in the $\mathrm{N}$-terminus of $\beta$-ENaC is partly responsible for the formation of the Cav3.2 / ENaC channel complex, but it is likely that other regions of $\beta$-ENaC are also involved.

\section{Cav3.2 and ENaC subunit affect each other's cell surface expression}

Next, we asked if $\beta$-ENaC subunit trafficking to the cell surface may be affected by co-expression of Cav3.2 channels in tsA cells. We detected a 2.5 fold increase in $\beta$-ENaC subunit surface pool (Fig. 4) when Cav3.2 channels were co-expressed. This result suggests that the formation of the Cav3.2/ $\beta$-ENaC complex either traffics more effectively to the cell surface, or that $\beta$-ENaC is 


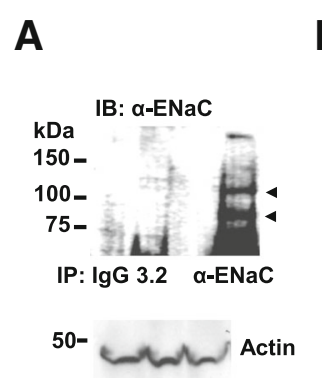

B

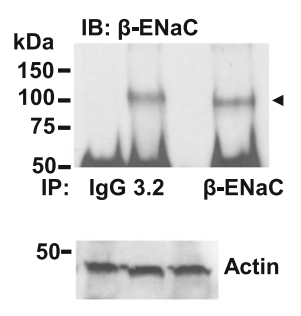

F

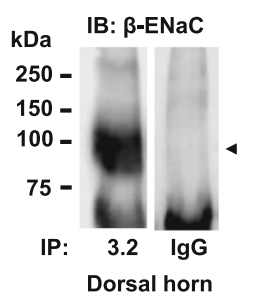

IB: $\boldsymbol{\alpha}$-Tubulin

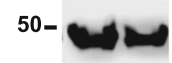

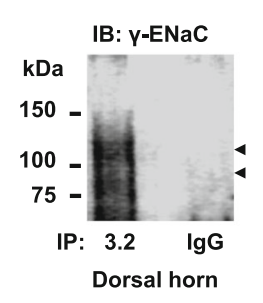

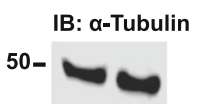

C

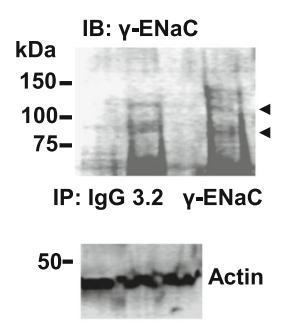

G
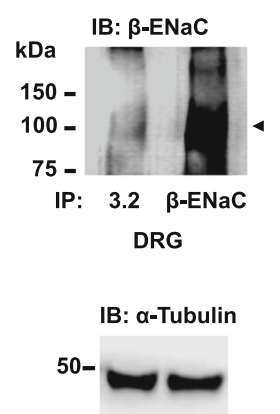

D

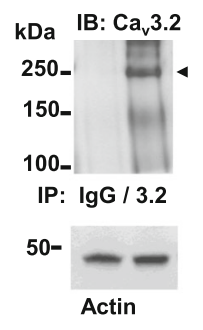

H
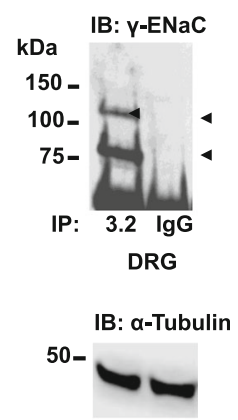

Fig. 1 Western blots showing Cav3.2 and ENaC complexes in neuronal tissue. Cav3.2 immunoprecipitates from mouse whole brain lysates were probed for either (a) $a-, n=3$ (b) $\beta-, n=3$ (c) $\gamma$-ENaC subunits, $n=3$ (arrows indicate full-length and cleaved proteins) or (d) Cav3.2 calcium channels, $n=4$. Actin loading controls are shown. (e) Cav3.2 immunoprecipitates from dorsal horn were probed for either $\beta$-ENaC, $n=3$ (IgG lane is cut) or $(\mathbf{f}) \gamma$-ENaC subunits, $n=3$ (arrows indicate full-length and cleaved proteins). a-Tubulin loading controls are shown. (g) Cav3.2 immunoprecipitates from lumbar dorsal root ganglia (L3-L6) were probed for either $\beta$-ENaC, $n=3$ or (h) $\gamma$-ENaC subunits, $n=3$ (arrows indicate full-length and cleaved proteins). a-Tubulin loading controls are shown

stabilized in the plasma membrane once incorporated into a complex with Cav3.2.

We next asked if $\mathrm{ENaC}$ promotes a reciprocal trafficking of Cav3.2 to the plasma membrane. We performed surface biotinylation assays coupled with western blot analysis. We did not detect a significant increase in the surface pool of Cav3.2 channels (Fig. 5a, b) when $\beta$-ENaC or $\gamma$-ENaC subunits were individually coexpressed with calcium channels in tsA-201 cells. In contrast, there was a 2 -fold increase in Cav3.2 cell surface expression when all three $\alpha \beta \gamma$-ENaC subunits were co-expressed with the calcium channels (Fig. 5a, b). These results suggest that fully assembled $\alpha \beta \gamma$-ENaC channels can increase the number of Cav3.2 calcium channels at the plasma membrane, at least in tsA-201 cells.

\section{Functional effects on Cav3.2 channel currents}

To investigate the effects of fully assembled $\alpha \beta \gamma$-ENaC channels on Cav3.2 current activity, we first coexpressed Cav3.2 channels and $\alpha \beta \gamma-\mathrm{ENaC}$ channels in tsA-201 cells. However, we noted very large leak currents that were toxic to the cells, and that could not be fully inhibited by adding the $\mathrm{ENaC}$ blocker amiloride to the cell culture medium. Instead, we compared whole cell currents recorded from cells expressing Cav3.2 channels in absence and presence of $\beta-\mathrm{ENaC}$ subunits which by themselves do not support ionic currents. We did not find any effect on the voltage-dependence of activation and whole cell current density (Additional file 1: Figure S1A and inset), or steady state inactivation (Additional file 1: Figure S1B and inset) of Cav3.2 channels. There was also no effect on activation and inactivation kinetics (data not shown). The absence of an effect on whole cell current density is consistent with the cell surface biotinylation experiment shown in Fig. 5b.

To ascertain if fully assembled $\mathrm{ENaC}$ channels may affect Cav3.2 channel activity, we instead transfected CAD cells which endogenously express Cav3.2. Cells were grown in medium supplemented with amiloride, which was then washed off prior to recordings. Currents were elicited every $5 \mathrm{mV}$ from a holding potential of $100 \mathrm{mV}$ to test different voltages. Figure $5 \mathrm{c}$ shows average current densities $(\mathrm{pA} / \mathrm{pF})$ as function of membrane voltage, revealing that $\alpha \beta \gamma-E N a C$ expressing cells show significantly larger $\mathrm{T}$-type currents compared to those of the control condition $(p<0.05)$. These data strongly implicate $\alpha \beta \gamma-\mathrm{ENaC}$ in regulating macroscopic T-type current amplitude (Fig. 5c, d). There was, however, no effect on the half-activation potential (Fig. $5 \mathrm{c}$ inset). 


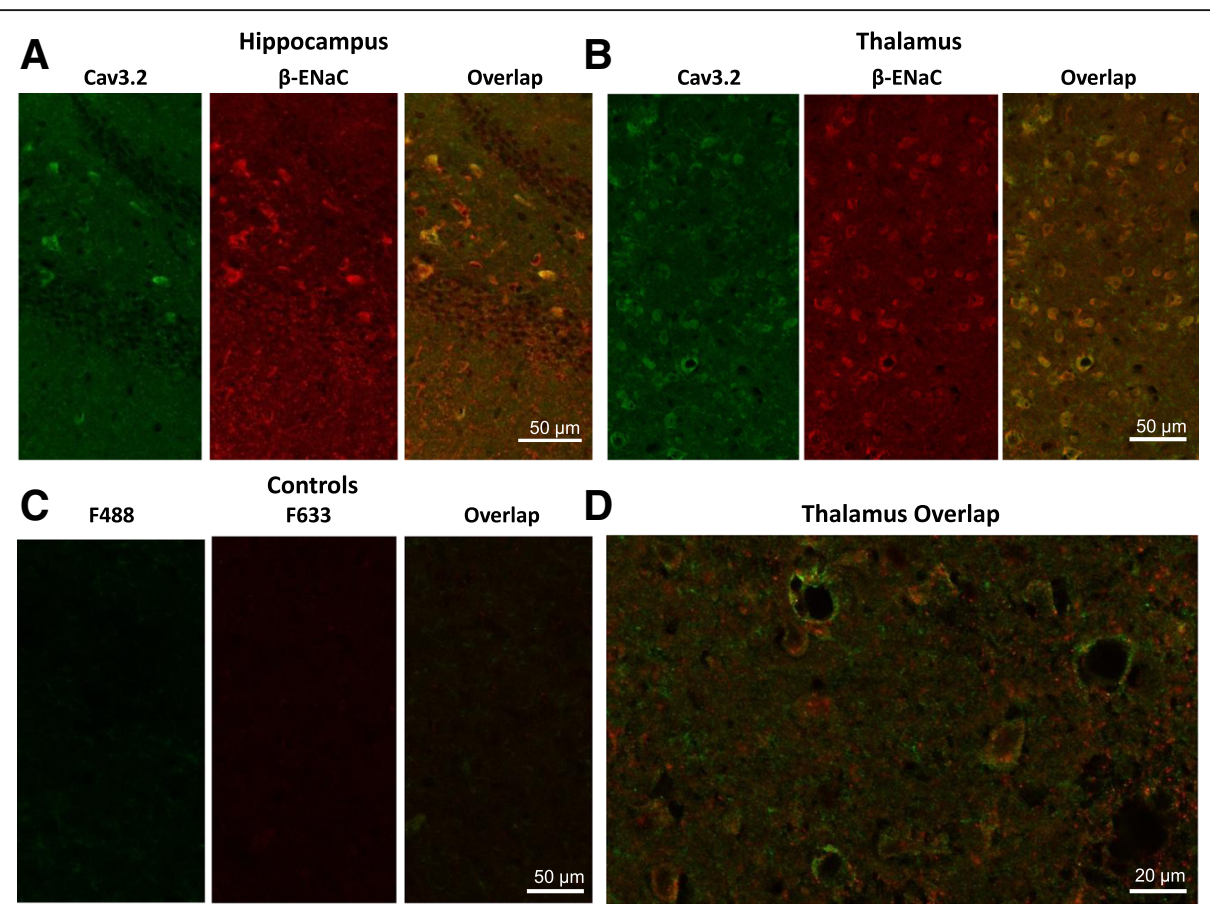

Fig. 2 Brain slices showing colocalization of Cav3.2 and $\beta$-ENaC in the thalamus and hippocampus. Staining of brain slices with mouse Cav3.2 (green) and polyclonal $\beta$-ENaC (red) antibodies. Four mouse brain slices were analyzed in each case. (a, b) Hippocampal (a) and thalamic (b) slice confocal images stained with Cav3.2 (green) or $\beta$-ENaC (red) antibodies are shown. (c) Negative controls using secondary antibodies only (Alexa F488 (green) and Alexa F633 (red)) are shown. (d) Larger magnification of immunostaining of thalamic cells stained with both antibodies

Altogether, these experiments strongly suggest that fully assembled $\alpha \beta \gamma$-ENaC channels are capable of modulating Cav3.2 calcium currents.

\section{Discussion}

The present study reveals the existence of a protein complex between Cav3.2 calcium channels and $\mathrm{ENaC}$ in the central and peripheral nervous systems. We detected robust co-expression of this channel complex in neurons from the thalamus, hypothalamus, hippocampus, lumbar dorsal root ganglia and dorsal horn by means of immunohistochemistry and co-immunoprecipitation assays. We also identified a cluster of lysines present in the cytosolic N-terminus tail of $\beta$-ENaC (K4R/ K5R/ K9R/ K16R/ K23R, mouse sequence) that is in part responsible for the formation of this complex with Cav3.2 channels. Co-expression of Cav3.2 channels with $\alpha \beta \gamma-\mathrm{ENaC}$ resulted in a significant increase in peak current density, demonstrating a functional role for the Cav3.2/ $\alpha \beta \gamma$ $\mathrm{ENaC}$ interaction. The increased current density, without apparent changes in current kinetics, in conjunction with increased cell surface abundance of Cav3.2 channels when $\alpha \beta \gamma-\mathrm{ENaC}$ was co-expressed suggests an increase in the numbers of Cav3.2 channels in the plasma membrane. This could be mediated either by an increase in forward trafficking, or by an increase in the stabilization of the channels in the plasma membrane. We do not know how ENaC mediates this effect, however, one possibility may be through an action on the ubiquitination levels of Cav3.2, which we have previously shown to potently regulate cell surface expression of these channels [13].

Although $\beta$-ENaC subunits can mediate this interaction, we did not observe any difference in current density when Cav3.2 channels were examined in the presence of $\beta$-ENaC subunits, suggesting that fully assembled $\alpha \beta \gamma$-ENaC channels are required for this effect. On the other hand, $\beta$-ENaC cell surface expression was enhanced in the presence of Cav3.2 suggesting that the $\beta$-ENaC subunit is sufficient for T-type channel interactions. We did not examine analogous effects on $\gamma$-ENaC subunit expression in tsA-201 cells, but we do note that this subunit has similar positively charged amino acids present in its cytosolic N-terminus tail such as K6, K8, $\mathrm{K} 10, \mathrm{~K} 12, \mathrm{~K} 13, \mathrm{~K} 26$ (mouse sequence). In contrast, the $\alpha-\mathrm{ENaC} \mathrm{N}$-terminus only possesses one lysine $\mathrm{K} 23$ from which one might predict a lack of interaction with Cav3.2 channels. Although $\beta$ - and $\gamma$-ENaC subunits consistently co-immnoprecipitate with Cav3.2 calcium channels from different neuronal tissues, we do not exclude the possibility that other protein partners are directly involved in the formation of Cav3.2 / ENaC complexes. For example, we have recently shown that Cav3.2 calcium channels can be clustered at the plasma membrane 
A

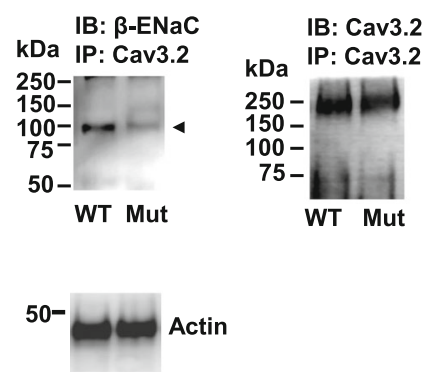

B

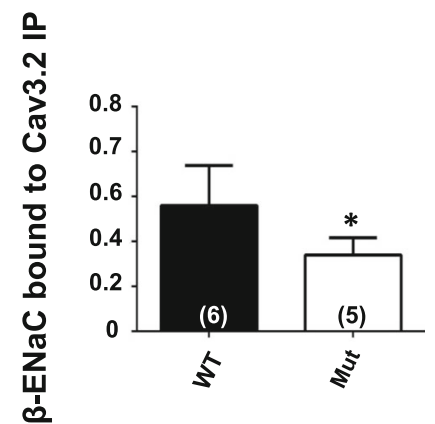

Fig. $3 \beta$-ENaC N-terminus lysines contribute to Cav3.2interactions. (a) Cav3.2 immunoprecipitates from tsA201 cells transfected with either wild type (WT) $\beta$-ENaC or mutant (Mut) $\beta$-ENaC (K4R/ K5R/ K9R/ K16R/ K23R) subunits were probed for $\beta$-ENaC, $n=5-6$. Membranes were stripped and probed for Cav3.2 by Western blot. Actin loading controls are shown, $n=5-6$. (b) Quantification analysis of $\beta$-ENaC bound to Cav3.2 immunoprecipitates

via spectrin / ankyrin B binding [26]. Spectrin is a highly abundant cytoskeletal protein in the nervous system $[27,28]$ and $\mathrm{ENaC}$ can also bind to both ankyrin and spectrin $[29,30]$, suggesting these cytoskeletal elements as a possible link between these channels. What is, however, curious is that we observed functional effects of $\alpha \beta \gamma$ $\mathrm{ENaC}$ on Cav3.2 channels in CAD cells, whereas we could not detect co-immunoprecipitation of $\alpha-\mathrm{ENaC}$ with Cav3.2 in brain tissue. This is not due to a lack of expression of $\alpha-\mathrm{ENaC}$ itself in the brain (see control lane in Fig. 1a). It is important to note that the functional effects on Cav3.2 channels in CAD cells involved the exogenous and thus artificial expression of all three $\mathrm{ENaC}$ subunits, and it is possible that $\alpha$-ENaC expression in the brain may be restricted to neurons that may not endogenously express high levels of Cav3.2, thus accounting for our inability to co-immunoprecipiate Cav3.2 with $\alpha$-ENaC.
Alternatively, there are several splice isoforms of $\alpha-\mathrm{ENaC}$ and it is possible that Cav3.2 channels selectively interact with a variant that is not picked up with the used antibody which is directed against an epitope in the $\mathrm{N}$-terminus where some splice variation can occur. It is also interesting to note that sensory neurons appear to only express $\beta$ and $\gamma-\mathrm{ENaC}$ subunits [11], thus raising the question as to what the function of these subunits may be in the absence of detectable levels of $\alpha-\mathrm{ENaC}$, at least under normal physiological conditions. It is possible that $\alpha-\mathrm{ENaC}$ expression might be induced under certain pathological conditions.

Interestingly, Younger and colleagues recently described that presynaptic DEG/ENaC channels made of pickpocket11 (PPK11) and pickpocket16 (PPK16) genes are responsible for both the acute induction and long term expression and maintenance of homeostatic
A

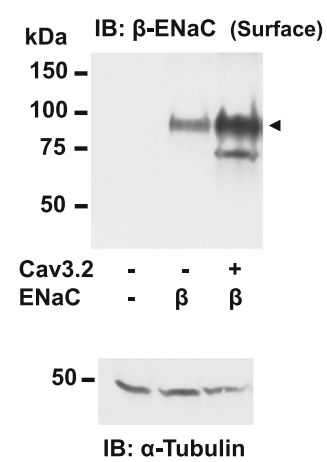

B

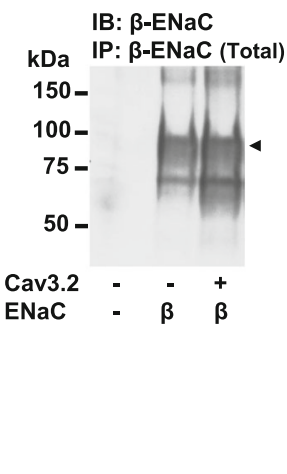

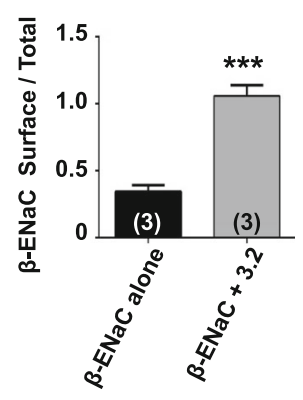

Fig. 4 Cav3.2 calcium channels promote trafficking of $\beta$-ENaC subunits to the cell surface. (a) Western blot showing $\beta$-ENaC surface and total pools from tsA201 cells labelled with biotin and transfected with either Cav3.2 alone or Cav3.2 + $\beta$-ENaC subunits, $n=3$. (b) Quantification of $\beta$-ENaC surface pool levels. An a-tubulin loading control is shown 

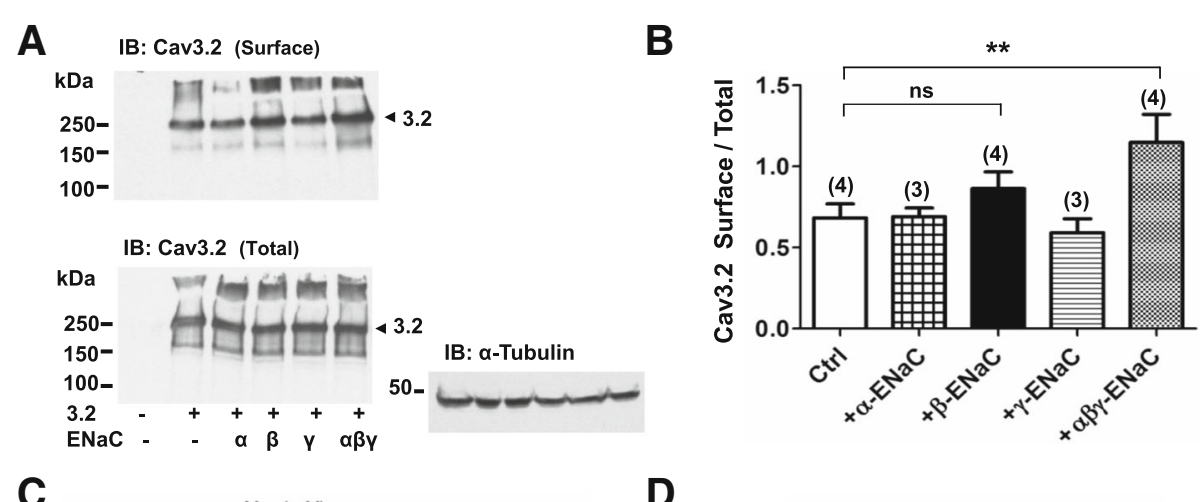

C
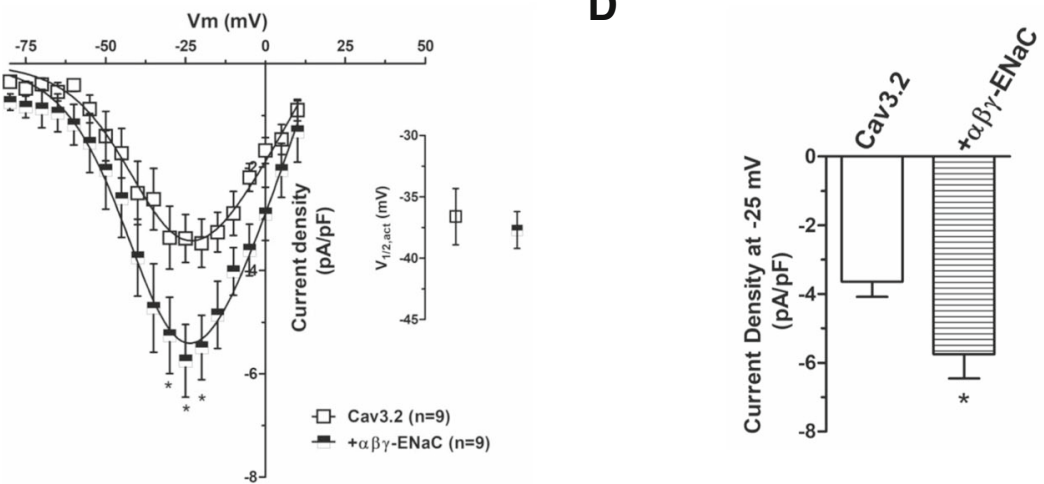

Fig. 5 a $\beta \gamma$-ENaC mediated effects on Cav3.2 surface pool and calcium currents. (a) a $\beta \gamma$-ENaC increases the Cav3.2 surface pool in tsA201. Cells were labelled with biotin and transfected with either Cav3.2 alone or Cav3.2 $+a-, \beta-$, or $\gamma$ - ENaC subunits individually or Cav3.2 + a $\beta \gamma$-ENaC fully assembled channels, $n=3-4$. An a-tubulin loading control is shown. (b) Quantification analysis of Cav3.2 surface pool. Statistical analysis was performed with ANOVA. (c) aßY-ENaC significantly increases Cav3.2 peak current density. Average current densities (pA/pF) as a function of voltage in CAD cells transfected with empty plasmid (open squares) or a $\beta \gamma$-ENaC (black and white squares). Inset: voltage for half activation. (d) Peak current density measured at $-25 \mathrm{mV}$ in absence or presence of aßY-ENaC. Cells were incubated with $100 \mathrm{nM}$ amiloride which was washed off before experimentation

synaptic plasticity at the neuromuscular junctions of Drosophila motor neurons [31]. In their proposed model these authors suggested that the increased sodium influx leads to a change in presynaptic resting potential which in turn directly or indirectly leads to an increase in presynaptc calcium influx via Cav2.1 calcium channels. This example of $\mathrm{ENaC}$ and Cav2.1 channels working in concert to maintain the homeostatic synaptic plasticity raises the possibility that interactions between $\mathrm{ENaC}$ and Cav3.2 channels could also be important for fine tuning synaptic activity. This may include the afferent pain pathway where Cav3.2 channels have been shown to regulate synaptic activity in the dorsal horn [12, 13, 32] and hippocampal circuits where Cav3.2 channels have been shown to fine tune NMDA receptor mediated synaptic transmission [33].

It is also important to reiterate that $\mathrm{ENaC}$ channel activity in kidney cells is regulated by intracellular calcium ions [22]. It is known that the kidney expresses T-type calcium channels [34] and it is therefore conceivable that Cav3.2 channels could provide the calcium source needed for calcium dependent regulation of $\mathrm{ENaC}$ channels. Experiments designed to examine the effects of
Cav3.2-mediated calcium entry on $\mathrm{ENaC}$ channel function will provide insights into such a possibility.

Altogether, we have identified the existence of a protein complex involving Cav3.2 and $\mathrm{ENaC}$ channels. Further work will be needed to elucidate the physiological significance of this interaction in neuronal and perhaps non neuronal tissues.

\section{Additional file}

Additional file 1: Figure S1. $\beta-E N a C$ does not modify Cav3.2 currents or biophysical parameters. (DOCX 195 kb)

\section{Abbreviations}

CAD cell: Cath (catecholaminergic)-a-differentiated; CFTR: Cystic Fibrosis transmembrane conductance regulator; DRG: Dorsal root ganglia; ENaC: Epithelial Sodium Channel; NMDA: N-methyl-D-aspartate;

PPK11: Pickpocket11; PPK16: Pickpocket16

\section{Acknowledgments}

Not Applicable.

\section{Funding}

This work was supported by a grant to GWZ from the Natural Sciences and Engineering Research Council. GWZ holds a Canada Research Chair. SH is supported by an Alberta Innovates Studentship, MAG is supported by 
Alberta Innovates and a Fellowship from the Canadian Institutes of Health Research.

\section{Availability of data and materials}

The data used in our study are available from the authors on reasonable request.

\section{Authors' contributions}

AG-C and GWZ designed the study and wrote the manuscript. GWZ supervised the study. AG-C, MAG, SH, YD, IAS, JMS and LC performed experiments and data analysis. All authors read and approved the final manuscript

\section{Ethics approval and consent to participate}

Not applicable.

\section{Consent for publication}

Not applicable.

\section{Competing interests}

The authors declare that they have no competing interests.

\section{Publisher's Note}

Springer Nature remains neutral with regard to jurisdictional claims in published maps and institutional affiliations.

\section{Author details}

${ }^{1}$ Molecular Neuroscience, Department of Physiology and Pharmacology, Hotchkiss Brain Institute and Alberta Children's Hospital Research Institute, Cumming School of Medicine, University of Calgary, 3330 Hospital Dr. NW, Calgary T2N 4N1, Canada. ${ }^{2}$ Cystic Fibrosis Center, University of North Carolina at Chapel Hill, Chapel Hill, NC, USA.

Received: 26 October 2018 Accepted: 4 February 2019

Published online: 08 February 2019

\section{References}

1. Benos DJ, Awayda MS, Berdiev BK, et al. Diversity and regulation of amiloride-sensitive Na+ channels. Kidney Int. 1996:49(6):1632-7.

2. Boucher RC. New concepts of the pathogenesis of cystic fibrosis lung disease. Eur Respir J. 2004:23(1):146-58.

3. Schild L. The epithelial sodium channel: from molecule to disease. Rev Physiol Biochem Pharmacol. 2004;151:93-107. https://doi.org/10.1007/ s10254-004-0023-7[published Online First: Epub Date]|

4. Schild $\mathrm{L}$. The ENaC channel as the primary determinant of two human diseases: Liddle syndrome and pseudohypoaldosteronism. Nephrologie. 1996;17(7):395-400.

5. Livraghi-Butrico A, Wilkinson KJ, Volmer AS, et al. Lung disease phenotypes caused by overexpression of combinations of alpha-, beta-, and gammasubunits of the epithelial sodium channel in mouse airways. American journal of physiology Lung cellular and molecular physiology. 2018;314(2): L318-L31. https://doi.org/10.1152/ajplung.00382.2017[published Online First: Epub Date]|

6. Benos DJ, Stanton BA. Functional domains within the degenerin/epithelial sodium channel (Deg/ENaC) superfamily of ion channels. J Physiol 1999:520 Pt 3:631-44

7. Bubien JK, Ismailov BBK II, et al. Liddle's disease: abnormal regulation of amiloride-sensitive $\mathrm{Na}+$ channels by beta-subunit mutation. Am J Phys. 1996;270(1 Pt 1):C208-13. https://doi.org/10.1152/ajpcell.1996.270.1. C208[published Online First: Epub Date]|.

8. Gentzsch M, Dang H, Dang Y, et al. The cystic fibrosis transmembrane conductance regulator impedes proteolytic stimulation of the epithelial $\mathrm{Na}$ + channel. J Biol Chem. 2010;285(42):32227-32. https://doi.org/10.1074/jbc. M110.155259[published Online First: Epub Date]|

9. Mistry AC, Wynne BM, Yu L, et al. The sodium chloride cotransporter (NCC) and epithelial sodium channel (ENaC) associate. The Biochemical journal. 2016;473(19):3237-52. https://doi.org/10.1042/BCJ20160312[published Online First: Epub Date]|.

10. Fricke B, Lints $\mathrm{R}$, Stewart $\mathrm{G}$, et al. Epithelial $\mathrm{Na}$ + channels and stomatin are expressed in rat trigeminal mechanosensory neurons. Cell Tissue Res. 2000; 299(3):327-34
11. Drummond HA, Abboud FM, Welsh MJ. Localization of beta and gamma subunits of ENaC in sensory nerve endings in the rat foot pad. Brain Res. 2000;884:1-2):1-12.

12. Jacus MO, Uebele VN, Renger JJ, Todorovic SM. Presynaptic Cav3.2 channels regulate excitatory neurotransmission in nociceptive dorsal horn neurons. Neurosci. 2012;32(27):9374-82.

13. Garcia-Caballero A, Gadotti VM, Stemkowski P, et al. The deubiquitinating enzyme USP5 modulates neuropathic and inflammatory pain by enhancing Cav3.2 channel activity. Neuron. 2014;83(5):1144-58.

14. Perez-Reyes E. Molecular physiology of low-voltage-activated t-type calcium channels. Physiol Rev. 2003;83(1):117-61.

15. Huguenard JR. Prince DA. A novel T-type current underlies prolonged $\mathrm{ca}(2$ + )-dependent burst firing in GABAergic neurons of rat thalamic reticular nucleus. J Neurosci. 1992;12(10):3804-17.

16. Heron SE, Khosravani $H$, Varela D, et al. Extended spectrum of idiopathic generalized epilepsies associated with $\mathrm{CACNA} 1 \mathrm{H}$ functional variants. Ann Neurol. 2007;62(6):560-8. https://doi.org/10.1002/ana.21169[published Online First: Epub Date]|

17. Zamponi GW, Lory P, Perez-Reyes E. Role of voltage-gated calcium channels in epilepsy. Pflugers Archiv : European journal of physiology. 2010;460(2): 395-403.

18. Khosravani H, Altier C, Simms B, et al. Gating effects of mutations in the Cav3.2 T-type calcium channel associated with childhood absence epilepsy. J Biol Chem. 2004;279(11):9681-4. https://doi.org/10.1074/jbc.C400006200[published Online First: Epub Date].

19. Anderson D, Mehaffey $\mathrm{WH}$, Iftinca $\mathrm{M}$, et al. Regulation of neuronal activity by Cav3-Kv4 channel signaling complexes. Nat Neurosci. 2010;13(3):333-7.

20. Rehak R, Bartoletti TM, Engbers JD, Berecki G, Turner RW, Zamponi GW. Low voltage activation of KCa1.1 current by Cav3-KCa1.1 complexes. PLoS One. 2013:8(4):e61844.

21. Turner RW, Kruskic M, Teves M, Scheidl-Yee T, Hameed S, Zamponi GW. Neuronal expression of the intermediate conductance calcium-activated potassium channel KCa3.1 in the mammalian central nervous system. Pflugers Archiv : European journal of physiology. 2015;467(2):311-28.

22. Gu Y. Effects of $[\mathrm{Ca} 2+] \mathrm{i}$ and $\mathrm{pH}$ on epithelial $\mathrm{Na}+$ channel activity of cultured mouse cortical collecting ducts. J Exp Biol 2008;211(Pt 19): 3167-3173 doi: https://doi.org/10.1242/jeb.019646[published Online First: Epub Date]|.

23. Rao US, Baker JM, Pluznick JL, Balachandran P. Role of intracellular Ca2+ in the expression of the amiloride-sensitive epithelial sodium channel. Cell Calcium. 2004;35(1):21-8.

24. Taruno A, Niisato N, Marunaka Y. Intracellular calcium plays a role as the second messenger of hypotonic stress in gene regulation of SGK1 and $\mathrm{ENaC}$ in renal epithelial A6 cells. American journal of physiology Renal physiology. 2008;294(1):F177-86. https://doi.org/10.1152/ajprenal.00250. 2007[published Online First: Epub Date]|.

25. Weiss N, Hameed S, Fernandez-Fernandez JM, et al. A ca(v)3.2/syntaxin-1A signaling complex controls T-type channel activity and low-threshold exocytosis. J Biol Chem. 2012;287(4):2810-8.

26. Garcia-Caballero A, Zhang FX, Hodgkinson V, et al. T-type calcium channels functionally interact with spectrin (alpha/beta) and ankyrin B. Molecular brain. 2018;11(1):24. https://doi.org/10.1186/s13041-018-0368-5[published Online First: Epub Date]|.

27. Zagon IS, McLaughlin PJ, Goodman SR. Localization of spectrin in mammalian brain. J Neurosci. 1984;4(12):3089-100.

28. Goodman SR, Zagon IS. Brain spectrin: a review. Brain Res Bull. 1984;13(6): 813-32.

29. Rotin D, Bar-Sagi D, O'Brodovich $\mathrm{H}$, et al. An SH3 binding region in the epithelial $\mathrm{Na}+$ channel (alpha $\mathrm{rENaC}$ ) mediates its localization at the apical membrane. EMBO J. 1994;13(19):4440-50.

30. Zuckerman JB, Chen X, Jacobs JD, Hu B, Kleyman TR, Smith PR. Association of the epithelial sodium channel with Apx and alpha-spectrin in A6 renal epithelial cells. J Biol Chem. 1999;274(33):23286-95

31. Younger MA, Muller M, Tong A, Pym EC, Davis GW. A presynaptic ENaC channel drives homeostatic plasticity. Neuron. 2013;79(6):1183-96. https:// doi.org/10.1016/j.neuron.2013.06.048[published Online First: Epub Date]|

32. Stemkowski P, Garcia-Caballero A, De Maria Gadotti V, et al. TRPV1 nociceptor activity initiates USP5/T-type channel-mediated plasticity. Cell Rep. 2017;18(9):2289-90.

33. Wang G, Bochorishvili G, Chen Y, et al. CaV3.2 calcium channels control NMDA receptor-mediated transmission: a new mechanism for absence 
epilepsy. Genes Dev. 2015;29(14):1535-51. https://doi.org/10.1101/gad. 260869.115[published Online First: Epub Date]|.

34. Hansen PB. Functional importance of T-type voltage-gated calcium channels in the cardiovascular and renal system: news from the world of knockout mice. American journal of physiology Regulatory, integrative and comparative physiology. 2015;308(4):R227-37. https://doi.org/10.1152/ajpregu. 00276.2014[published Online First: Epub Date]|.

Ready to submit your research? Choose BMC and benefit from:

- fast, convenient online submission

- thorough peer review by experienced researchers in your field

- rapid publication on acceptance

- support for research data, including large and complex data types

- gold Open Access which fosters wider collaboration and increased citations

- maximum visibility for your research: over $100 \mathrm{M}$ website views per year

At $\mathrm{BMC}$, research is always in progress.

Learn more biomedcentral.com/submissions 